$16^{\circ}$ USIHC - Congresso Internacional de Ergonomia e Usabilidade de CINAHPA

\title{
METODOLOGIA PARTICIPATIVA DE ANÁLISE DE ACESSIBILIDADE EM CALÇADAS
}

\section{PARTICIPATORY METHODOLOGY OF ANALYSIS OF ACCESSIBILITY IN SIDEWALK}

\author{
Aline Eyng Savi ${ }^{1}$, M.Sc. \\ Lays Juliani Hespanhol ${ }^{2}$, Graduanda. \\ (1) Universidade do Extremo Sul Catarinense \\ e-mail:arquiteta.alinesavi@gmail.com \\ (2) Universidade do Extremo Sul Catarinense \\ e-mail:laysjulianih@hotmail.com
}

Acessibilidade, Calçadas, Desenho Universal

Os espaços livres públicos são locais não edificados. Neles, as barreiras físicas restringem os cidadãos. O objetivo é avaliar acessibilidade e propor diretrizes de projeto para as calçadas. A metodologia é "Active Design: Shaping the Sidewalk Experience" e o Passeio Acompanhado. Os resultados contemplam as normas e o Desenho Universal.

\section{Accessibility, Sidewalks, Universal Design}

Free spaces are the undeveloped places. In them, as physical barriers restrict citizens. The goal is to assess accessibility and propose design guidelines for sidewalks. The methodology is "Active design: Shaping the sidewalk experience" and the Accompanied Walk. The results contemplate the norms and the Universal Design. 


\section{$16^{\circ}$ \\ ERGODESIGN USIHC CINAHPA}

\section{Introdução}

Os espaços livres públicos são locais não edificados e formam uma trama na malha urbana das cidades. Compõem-se num sistema complexo de interconexões, com ambientes de lazer, contemplação, ócio, circulação, conforto, conservação e requalificação ambiental, drenagem, memória urbana e recreação. Tais características evidenciam a importância social que estes locais tem perante a cidade, já que influenciam na qualidade de vida humana.

Nesse sentido, garantir que toda a população tenha acesso a esses locais, extingue que uma parcela dos cidadãos fiquem isolados, sem conseguir transitar pelos espaços por falta de acessibilidade espacial. Pessoas com deficiência e restrições encontram vários obstáculos ao se deslocarem pelos espaços livres públicos.

Dessa maneira, tornar o espaço livre público acessível é abolir os barreiras físicas, naturais ou de comunicação que existem e impedem a circulação das pessoas nas calçadas, praças, parques, equipamentos, mobiliários, edifícios e no transporte público. No Brasil, uma publicação recente (CPA/SMPED, 2006) descreve todas as características que deve possuir uma via pública, dentre elas ser acessível, de modo a prever mobilidade para todos os usuários, assegurando o acesso.

Assim, estrutura-se o projeto: "Acessibilidade para todos em espaços livres públicos", financiado pelo Programa Institucional de Bolsas de Iniciação Científica (PIBIC). O objetivo é a avaliação pósocupação das condições de acessibilidade nas calçadas de um recorte da cidade de Criciúma, sul de Santa Catarina, Brasil, e propor ao término, diretrizes de projeto com base no cenário encontrado. A escolha do recorte e das calçadas como espaço livre público de estudo ocorreu mediante caracterização prévia de maior carência desse quesito no cenário urbano. A metodologia adotada avalia a pós-ocupação considerando: segurança, mobiliário urbano, acessibilidade, conectividade, escala do pedestre, complexidade, $16^{\circ}$ Ergodesign - Congresso Internacional de Ergonomia e Usabilidade de Interfaces Humano Tecnológica: Produto, Informações Ambientes Construídos e Transporte

$16^{\circ}$ USIHC - Congresso Internacional de Ergonomia e Usabilidade de Interfaces Humano Computador

CINAHPA | 2017 - Congresso Internacional de Ambientes Hipermídia para Aprendizagem.

sustentabilidade e resiliência climática a partir da metodologia "Active Design: Shaping the Sidewalk Experience". Para aprofundar as informações acerca da acessibilidade nas calçadas, foi utilizada a metodologia dos Passeios Acompanhados (DISCHINGER, 2000).

\section{Referencial teórico}

Visando a sustentabilidade social, a metodologia de análise deste trabalho foi efetuada através da experiência do usuário, relacionada com a base teórica produzida que impulsionou a compreensão dos princípios de elaboração deste. Os principais títulos são apresentados a seguir.

\subsection{Acesso e Acessibilidade}

Numa visão mais abrangente Kevin Lynch descreve o acesso como um elemento fundamental para se atingir um bom sistema e forma de cidade. Segundo Wright (2001), a maioria dos brasileiros utiliza a caminhada para exercer suas atividades e aproximadamente $80 \%$ das viagens realizadas nas cidades são feitas a pé. Uma vez que para utilizar o transporte público é necessário uma caminhada a pé até o ponto de deslocamento rápido, tornando claro a interdependência da mobilidade pública com os acessos produzidos nos espaços livres de uma cidade.

A acessibilidade segue junto com o acesso, numa relação de dependência no sentido de mobilidade pública, e pode ser definida como condição para utilizar com segurança e autonomia os edifícios, os espaço livres públicos, o mobiliário e os equipamentos urbanos, garantindo a locomoção plena de todos os cidadão (CARDOSO, 1992; COHEN, 1998; CONDE, 1994; HAZAN, 1994; UBIERNA, 1994; YÁZIGI, 2000).

A acessibilidade espacial diz respeito às características dos ambientes, de forma a permitir o acesso, o deslocamento, a orientação e o uso dos equipamentos por qualquer indivíduo, sem necessitar seu conhecimento prévio. É assegura por leis (e.g. Lei Federal n ${ }^{\circ}$ 10.098/2000 e Lei Brasileira de Inclusão $\left.{ }^{\circ} 13.146 / 2015\right)$, decretos (e.g. Decreto $\left.n^{\circ} 3.298 / 1999\right)$ e pela Associação 
Brasileira de Normas Técnicas (e.g. NBR 9050/2015).

Os espaços acessíveis devem ser projetados cautelosamente, corroborando autores como Cardoso (1992), Cohen (1998), Conde (1994), Hazan (1994), Ubierna (1994) e Yázigi (2000) sugerem algumas condicionantes como a eliminação de obstáculos nas calçadas; uso de textura especial para advertir o perigo; adoção de pisos não derrapantes; adoção de cruzamentos feitos por meio de rampas com cores e texturas diferentes; evitar rampas em sentido diagonal à intersecção; e o estudo preliminar antes da colocação do mobiliário.

\subsection{Espaços livres Públicos e Calçadas}

O espaço urbano é formado por ambientes construídos - áreas edificadas por residências, indústrias, comércio, serviços e arquiteturas institucionais, além dos espaços destinados às circulações de pessoas e veículos e dos resquícios não edificados definidos como "espaços livres de construção" (LIMA et al., 1994), são: quintais, jardins, ruas, avenidas, praças, parques, rios, matas, mangues, praias urbanas, ou simples vazios urbanos (MAGNOLI, 1982). A localização, acessibilidade e distribuição dessas estruturas formam um complexo sistema de conexões com múltiplos papéis urbanos e o caráter desses espaços livres pode ser público ou privado (MACEDO; CUSTÓDIO, et. al., 2009).

A caracterização do sistema de espaços livres públicos urbanos de uma cidade passa por questões como a identificação dos elementos

predominantes, localização, distribuição, acessibilidade física e simbólica,

complementaridade, interdependência, hierarquia, conectividade e articulação; além de aspectos como o formal e o funcional. Nessa classificação, os espaços livres públicos podem ser divididos pelos valores: estéticos/simbólicos, ambiental e recreativo (ROBBA; MACEDO, 2004). Dessas funções, a social destaca-se por proporcionar a retomada do conceito de sociedade e cidade, aumentando a qualidade de vida urbana. Logo, o suposto caráter democrático dos espaços livres $16^{\circ}$ Ergodesign - Congresso Internacional de Ergonomia e Usabilidade de Interfaces Humano Tecnológica: Produto, Informações Ambientes Construídos e Transporte

$16^{\circ}$ USIHC - Congresso Internacional de Ergonomia e Usabilidade de Interfaces Humano Computador

CINAHPA | 2017 - Congresso Internacional de Ambientes Hipermídia para Aprendizagem.

públicos precisa ser garantido para toda e qualquer pessoa, sem barreiras sociais, atidudinais e também, aquelas atribuídas ao desenho arquitetônico e paisagístico, que são as físicas e informativas.

Um dos espaços livres públicos mais utilizados no dia a dia do cidadão, é a calçada, fonte de acesso e conexão entre espaços construídos e livres.

Responsável pela condução da população, os passeios urbanos ou calçadas deveriam ser lugares agradáveis, seguros para prática da caminhada ou mesmo para outras atividades como o trabalho, estudo, socialização e circulação, mas acabaram ao longo dos anos por se tornar espaços cedidos quase que totalmente às vias de veículos. Isso prejudica todo o sistema de mobilidade urbana, sem conferir segurança para a circulação de pedestre, além de isolar uma parte da população por falta de acessibilidade.

\subsection{Desenho Universal e Espaço Inclusivo}

Com o objetivo de alcançar um conceito amplo de acessibilidade, a pesquisa adota o Desenho Universal, que consiste numa visão de projeto com o desenvolvimento de objetos, ambientes e edificações considerando a diversidade, desde os estudos preliminares do projeto (DISCHINGER, BINS ELY, BORGES, 2009; DISCHINGER et. al., 2006). O objetivo principal é disponibilizar, a partir de um desenho de qualidade, o fácil entendimento sobre o uso (legibilidade), a segurança e o conforto para todos. Logo não significa conceber "espaços especiais" para "pessoas especiais", mas dotar o espaço de qualidades que beneficiem a todos ou o maior universo possível. Este conceito é uma ferramenta que conduz à acessibilidade, porque permite " [...] poder chegar a algum lugar de forma independente, segura e com o mínimo de conforto; entender a organização e as relações espaciais que este lugar estabelece, e participar de todas as atividades que ali se desenvolvem fazendo uso dos equipamentos disponíveis" (DISCHINGER et. al., 2006).

Dessa maneira, ao viabilizar acessibilidade através do DU cria-se condição essencial para cidadania urbana, princípio para alcançar sustentabilidade

Realização:




\section{$16^{\circ}$ \\ ERGODESIGN USIHC CINAHPA}

social, através de espaços inclusivos, já que a experiência dos espaços estrutura os padrões de identificação do sujeito com o meio ambiente. Segundo Tuan (1983, p. 10), "[...] experienciar é aprender, compreender; significa atuar sobre o espaço e poder criar a partir dele". Portanto, é necessário que o processo cognitivo se desenvolva através da percepção e da apreensão do espaço para que o indivíduo possa conhecer e agir sobre ele.

\section{Metodologia}

A pesquisa "Acessibilidade para todos em espaços livres públicos" iniciou com visitas exploratórias ao recorte, em busca de caracterizar os espaços livres e identificar as maiores deficiências. Em paralelo foram elaborados materiais cartográficos acerca do tema. O recorte de estudo com extensão de $19,60 \mathrm{~km}^{2}$ corresponde a $8,36 \%$ do território municipal e nele se constatou que os espaços livres públicos se reduzem às áreas de recuperação ambiental, resultado da mineração de carvão a céu aberto e às vias de ligação (passeios públicos, ruas, avenidas, etc.). No que tange a acessibilidade física e informativa dos espaços livres públicos, é perceptível que os maiores problemas estão na infraestrutura e no mobiliário urbanos, através: da ausência de passeios ou sua má conservação e execução (Figura 01); falta de calçamento nas vias públicas (Figura 02); ineficácia ou ausência dos instrumentos de informação; falta de mobiliário urbano (como lixeiras e paradas de ônibus); escassez de espaços públicos de lazer (como praças e parques).

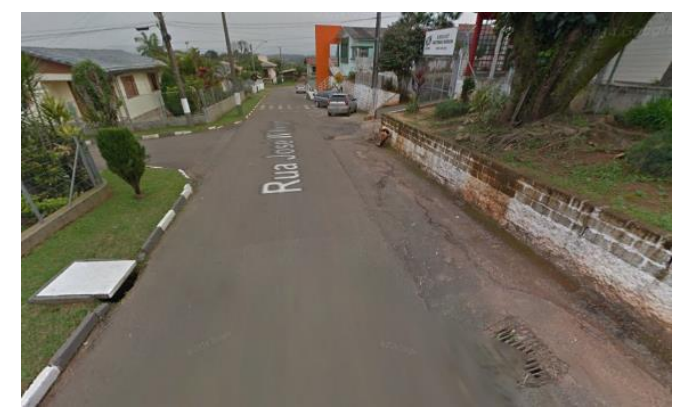

Figura 01. Rua do recorte da Grande Santa Luzia, com a falta de padrão ou ausência de passeio. Fonte: GoogleEarth, 2016. $16^{\circ}$ Ergodesign - Congresso Internacional de Ergonomia e Usabilidade de Interfaces Humano Tecnológica: Produto, Informações Ambientes Construídos e Transporte

$16^{\circ}$ USIHC - Congresso Internacional de Ergonomia e Usabilidade de Interfaces Humano Computador

CINAHPA | 2017 - Congresso Internacional de Ambientes Hipermídia para Aprendizagem.

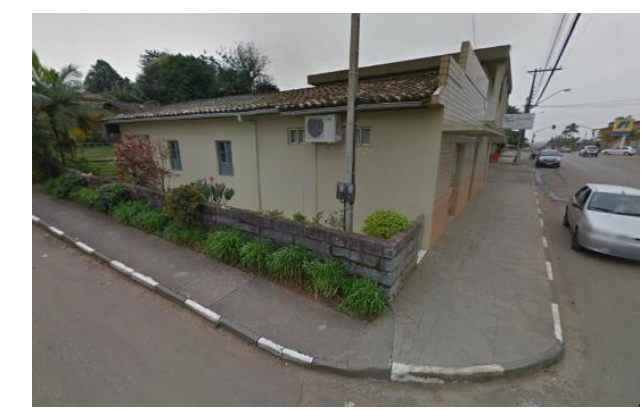

Figura 02. Rua do recorte da Grande Santa Luzia, com a falta de acessibilidade em esquina. Fonte: GoogleEarth, 2016.

A escolha do recorte e das calçadas como espaço livre público de estudo ocorreu mediante caracterização prévia de maior carência desse quesito no cenário urbano. A metodologia adotada avalia a pós-ocupação a partir da metodologia "Active Design: Shaping the Sidewalk Experience" [Projeto ativo: modelando a experiência da calçada, tradução nossa]. Para aprofundar as informações acerca da acessibilidade nas calçadas, foi utilizada também a metodologia dos Passeios Acompanhados (DISCHINGER, 2000). O método possibilita mapear as condições reais de uso do espaço por parte do usuário com deficiência, de forma a identificar, no exato momento em que ocorrem as atividades, os aspectos positivos e negativos do ambiente construído. A avaliação pósocupação a partir desses dois métodos permite efetiva participação da comunidade nas etapas de pesquisa. Essa metodologia foi aplicada numa amostra do recorte, escolhida pela representatividade urbana em razão de ser centralidade e possuir maior número de equipamentos públicos.

O primeiro método é aplicado através de três etapas (Figura 03) a serem completadas de acordo com a experiência do avaliador no local, que pode tomar notas, fazer croquis de auxílio e pontuar as calçadas em cada um dos tópicos que é observado. A primeira etapa chamada de "O passeio e suas fases" é caraterizada por escolher o local de análise e assim, com uma perspectiva, marcar os diferentes planos presentes na construção da imagem do passeio. Este são assim divididos: (01) Dossel: é o coroamento da imagem, formada por exemplo pelas marquises das edificações e o céu; (02) Parede do edifício: é o plano que marca o limite do
Realização:
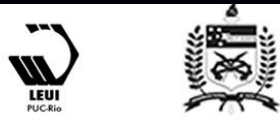


\section{$16^{\circ}$ \\ ERGODESIGN USIHC CINAHPA}

passeio através de edificações; (03) Plano da estrada: é o plano que marca o limite do passeio através da via de rolagem; e (04) Plano do Passeio: é o passeio ou calçada propriamente dita.

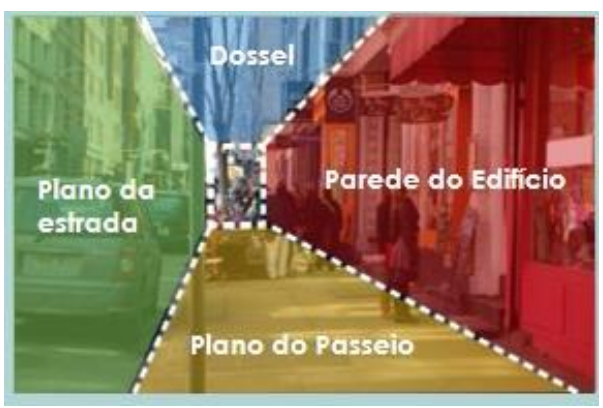

Figura 03: Tabela ilustrativa da metodologia baseada no Active Design: Shaping the Sidewalk Experience. Fonte: HESPANHOL, 2017.

A etapa seguinte é chamada de "O olhar do observador". Nela há a sensibilidade do observador, que através de seu olhar e experiência no local, levanta todos os pontos positivos e negativos de cada plano marcado na etapa anterior. $\mathrm{Na}$ pesquisa foram considerados: segurança, mobiliário urbano, acessibilidade, conectividade, escala do pedestre, complexidade, sustentabilidade e resiliência climática. Além disso, a etapa resgata e compara a realidade com as normas e leis vigoradas no espaço de análise, partindo assim para a última etapa do método, com o nome de "A solução com croqui". Nela é transposto o olhar do observador para o papel, buscando e solucionando os pontos levantados anteriormente.

A fim de aprofundar as informações acerca da acessibilidade nos passeios públicos sob a ótica dos maiores prejudicados no que tange a falta de acessibilidade, foi utilizado o método do Passeio Acompanhado (DISCHINGER, 2000). As etapas metodológicas consistem na realização de passeio no local de estudo, acompanhando pessoas que possuam algum tipo de deficiência ou restrição relevante para a pesquisa. O roteiro é previamente definido pelo grupo pesquisador. No percurso, os pesquisadores não devem ajudar ou conduzir o participante convidado como condição de não interferir nos resultados obtidos, a não ser que haja solicitação ou eminente perigo (PADARATZ; BINS ELY; DISCHINGER, 2005). Ao verbalizar $16^{\circ}$ Ergodesign - Congresso Internacional de Ergonomia e Usabilidade de Interfaces Humano Tecnológica: Produto, Informações Ambientes Construídos e Transporte

$16^{\circ}$ USIHC - Congresso Internacional de Ergonomia e Usabilidade de Interfaces Humano Computador

CINAHPA | 2017 - Congresso Internacional de Ambientes Hipermídia para Aprendizagem.

as ações, o participante convidado compartilha com os pesquisadores que o acompanham as decisões tomadas durante o percurso e os fatores que as motivaram. Dessa forma, a vivência real permite resultados mais precisos do que simples informações ou simulações. As conversas são gravadas e os pontos relevantes são transcritos. Os eventos significativos são fotografados e localizados em mapas sintéticos dos percursos.

Nessa pesquisa, o uso do Passeio Acompanhado demanda número expressivo de convidados, uma vez que os espaços livres públicos exigem soluções universais para os problemas de acessibilidade de uma gama variada de usuários. No artigo, é apresentado o passeio acompanhado com o cadeirante, porque a pesquisa ainda está em andamento. Registra-se que o mesmo percurso estabelecido para o cadeirante será aplicado para convidados idosos, deficientes visuais, mães com carrinho de bebê e pessoas com algum tipo de restrição motora temporária (por exemplo: uso de bengala).

Com os passeios caracterizados, foi definida a rota que se inicia num ponto de ônibus, percorre vias públicas e termina junto à escola pública municipal do bairro, num total de 250 metros. Tal delimitação percorre uma rota em que são percebidos os problemas de acessibilidade comuns do recorte, sendo eles: falta de calçamento ou de padrão nos passeios, falta de elementos de acessibilidade física e informativa, colocação equivocada de infraestrutura e mobiliário urbano.

O participante do passeio possui paralisia dos membros inferiores em razão de acidente de automóvel aos dezenove anos. Apesar do seu preparo físico, foi notório o esforço feito ao longo do percurso que tem suave inclinação, agravando ainda mais a ausência de recursos de acessibilidade. Registra-se que o participante já conhecia o percurso, de atividade anterior, permitindo estratégias para evitar grandes esforços e até mesmo perigo em algumas travessias. No trajeto constataram-se as barreiras físicas como: falta de rampa, descuido na manutenção de calçadas, passeios com material impróprio para o uso e a dificuldade que impossibilita o uso do
Realização:

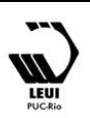




\section{$16^{\circ}$ \\ ERGODESIGN USIHC CINAHPA}

passeio e exige o uso da via pública (Figura 04).

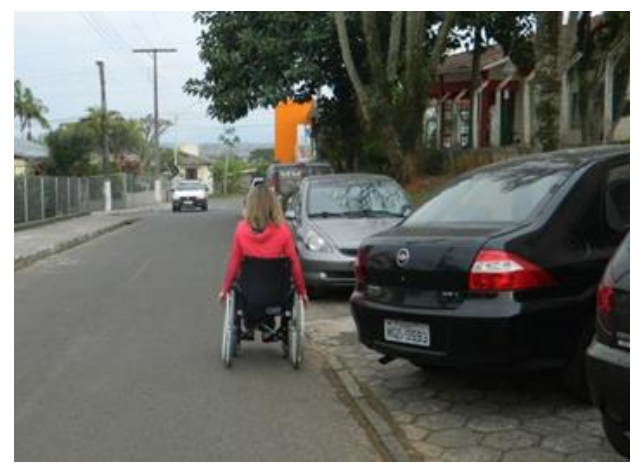

Figura 04: Percurso adotado no passeio acompanhado. Fonte: Ana Paula Albuquerque, 2016

\section{Resultados}

A metodologia "Active Design: Shaping the Sidewalk Experience" apresenta a área de estudo através de imagens perspectivadas, marcando quarto faces: Dossel, Plano da Estrada, Plano do Passeio e Parede do edifício. A primeira corresponde ao plano de cobertura, geralmente a abóboda celeste ou marquises. O plano de estrada, passeio e edifício correspondem respectivamente: via pública, piso do passeio público e borda de lotes. Nessa pesquisa, a face com maior destaque de análise foi Plano do Passeio, focando no objetivo principal de gerar proposta de acessibilidade.

A partir dos resultados da metodologia conjunto "Active Design" e do Passeio Acompanhado foram elaborados croquis de anotações e levantamentos das percepções vividas na área de estudo. As ilustrações apresentam o cenário real encontrado e as soluções projetuais universais aplicadas sobre ele. As propostas além de contemplarem as exigências da NBR 9050/2015, buscam qualificar os ambientes, atribuindo-lhes princípios do DU. O uso de croquis sobre imagens reais tem a função didática de compartilhamento com a comunidade. Tal recurso permite a fácil compreensão e especialmente, o reconhecimento da ambiência urbana permite despertar consciência nos cidadãos.

Nas Figuras 05 e 06, há a ilustração dos passeios públicos onde a diferenciação de pisos torna a $16^{\circ}$ Ergodesign - Congresso Internacional de Ergonomia e Usabilidade de Interfaces Humano Tecnológica: Produto, Informações Ambientes Construídos e Transporte

$16^{\circ}$ USIHC - Congresso Internacional de Ergonomia e Usabilidade de Interfaces Humano Computador

CINAHPA | 2017 - Congresso Internacional de Ambientes Hipermídia para Aprendizagem.

circulação acessível a todos. Há ainda, a presença de vegetação, importante elemento na configuração dos espaços abertos. Os pisos diferentes permitem o movimento livre e seguro ao usuário. $\mathrm{O}$ piso guia indica o percurso e o alerta impõem segurança. Ambos contribuem para independência no uso dos espaços livres públicos da cidade. A regularidade do piso e a dimensão do passeio também permitem que o deslocamento do cadeirante seja livre de obstáculos, através da criação de uma faixa exclusiva para o mobiliário urbano.

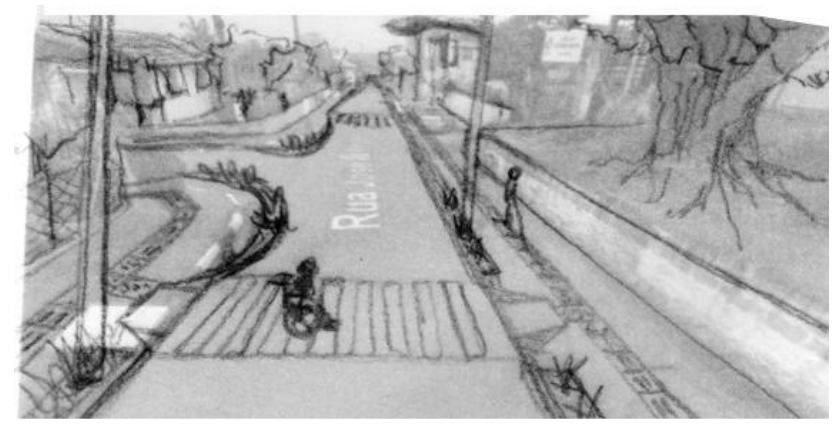

Figura 05: Rua do recorte da Grande Santa Luzia, com o tratamento os recursos de acessibilidade. Fonte: GoogleEarth, 2016.

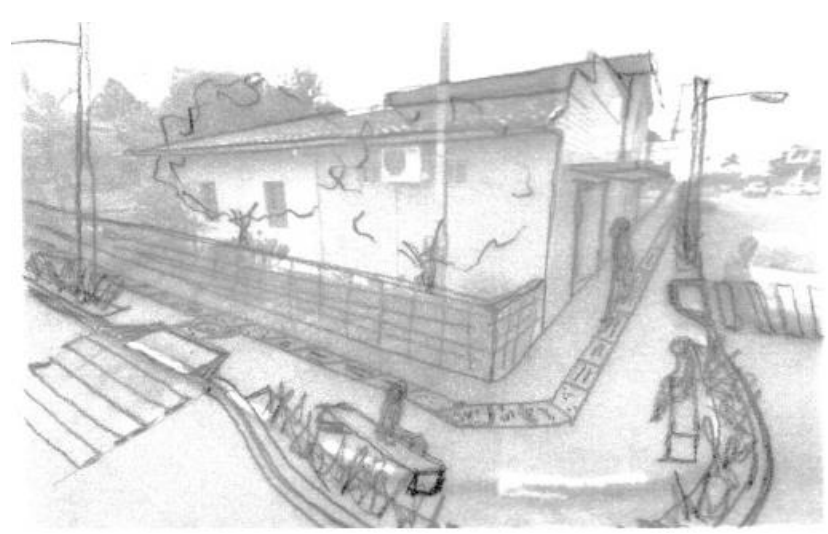

Figura 06: Rua do recorte da Grande Santa Luzia, com o tratamento os recursos de acessibilidade. Fonte: GoogleEarth, 2016.

\section{Considerações Finais}

Os resultados obtidos através dos estudos iniciais, apresentados neste trabalho, permitem as seguintes conclusões: 1. A percepção dos usuários em relação à importância dos atributos de caracterização da infraestrutura das calçadas e travessias das vias deve ser considerada, pois permite estabelecer uma ordem de prioridade das 


\section{$16^{\circ}$ \\ ERGODESIGN USIHC CINAHPA}

variáveis de definição dos aspectos de conforto e segurança; 2 . A avaliação técnica se mostrou eficiente e de fácil aplicação para o levantamento das condições atuais da infraestrutura das calçadas e travessia das vias, bem como suas características de projeto (concepção);

\section{BIBLIOGRAFIA}

ABNT NBR-9050: Acessibilidade a edificações, mobiliário, espaços e equipamentos urbanos. Associação Brasileiras de Normas Técnicas, Rio de Janeiro; ABNT, 2015.

\section{ACTIVE DESIGN: SHAPING THE SIDEWALK} EXPERIENCE. Disponível em:

$<$ https://www1.nyc.gov/assets/planning/download/ pdf/plans-studies/active-design-sidewalk $>$. Acesso em 15 dez. 2016.

ALEXANDER, Christopher et al. Urbanismo y participación. El caso de la Universidad de Oreg n Gustavo Gili, Barcelona, 1978.

COHEN, Regina; DUARTE, Cristiane Rose. Pesquisa e projeto de espaços públicos: rebatimentos e possibilidades de inclusão da diversidade física no planejamento das cidades. In: PROJETAR 2005 - II SEMINÁRIO SOBRE ENSINO E PESQUISA EM PROJETO DE ARQUITETURA, 2005, Rio de Janeiro. Anais do II PROJETAR. 2005.

DISCHINGER, Marta; BINS ELY, Vera Helena Moro; BORGES, Monna Michelle F. C. Manual de Acessibilidade Espacial para Escolas: o direito à escola acessível. Brasília: Ministério da Educação, Secretaria de Educação Especial, 2009.

DISCHINGER, Marta; et al. A importância do desenvolvimento de métodos de avaliação de acessibilidade espacial - estudo de caso no Colégio de Aplicação - UFSC. Núcleo de Pesquisa em Tecnologia da Arquitetura e Urbanismo - NUTAU. São Paulo: USP, 2006.

DISCHINGER, Marta. Designing for all senses: accessible spaces for visually impaired citizens. Göteborg, Suécia, 2000. - Department of Space and Process, School of Architecture, Chalmers University of Technology. $16^{\circ}$ Ergodesign - Congresso Internacional de Ergonomia e Usabilidade de Interfaces Humano Tecnológica: Produto, Informações Ambientes Construídos e Transporte

$16^{\circ}$ USIHC - Congresso Internacional de Ergonomia e Usabilidade de Interfaces Humano Computador

CINAHPA | 2017 - Congresso Internacional de Ambientes Hipermídia para Aprendizagem.
GADOTTI, Moacir. Município que educa: História, conceitos e fundamentos. Rede Social Município que Educa. São Paulo: Instituto Paulo Freire. 2009.

MACEDO, Silvio S.; CUSTÓDIO, Vanderli et al. Os sistemas de espaços livres da cidade contemporânea brasileira e a esfera de vida pública: considerações preliminares. In: Encúentro de Geógrafos de América Latina, $12^{\circ}$., 2009, Montevideo. Anais do XII EGAL, 3- 7 abril. Montevideo: Universidad de la República, 2009. p. $1-12$.

MAGNOLI, Miranda. Espaços livres e urbanização. Tese (Livre-docência) - FAUUSP, São Paulo, 1982.

LIMA, A. M. L. P.; CAVALHEIRO, F.; NUCCI, J. C.; SOUSA, M. A. L. B.; FIALHO, N. O.; DEL PICCHIA, P. C. D. Problemas de utilização na conceituação de termos como espaços livres, áreas verdes e correlatos. In: Congresso Brasileiro sobre Arborização Urbana, II; Encontro Nacional sobre Arborização Urbana, Anais... São Luís: Sociedade Brasileira de Arborização Urbana, 1994. p. 539553.

BRASIL. Cartilha do Censo 2010 - Pessoas com Deficiência/ Secretaria de Direitos Humanos da Presidência da República (SDH/PR) / Secretaria Nacional de Promoção dos Direitos da Pessoa com Deficiência (SNPD) / Coordenação-Geral do Sistema de Informações sobre a Pessoa com Deficiência; Brasília: SDH PR/SNPD, 2012.

PADARATZ, Rejane; BINS ELY, Vera Helena M.; DISCHINGER, Marta. Acessibilidade e inclusão no ensino para melhoria da qualidade de vida urbana. In: Anais do $1^{\circ}$ Congresso Luso-Brasileiro para o Planejamento Urbano, Regional, Integrado e Sustentável. São Paulo: USP, 2005.

PATRÍCIO, Z. M. Introdução à prática de pesquisa socioambiental. Apostila. Curso de especialização em Gestão de Recursos Hídricos. Departamento de Engenharia Sanitária e Ambiental - UFSC, 2005. $102 p$.

ROBBA, F.; MACEDO, S. S. Praças Brasileiras. Estudos Geográficos: Revista Eletrônica de Geografia, Rio Claro, v. 2, jul - dez - 2004. p. 8788.
Realização:

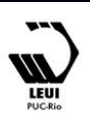




\section{$16^{\circ}$ \\ ERGODESIGN USIHC CINAHPA}

$16^{\circ}$ Ergodesign - Congresso Internacional de Ergonomia e Usabilidade de Interfaces Humano Tecnológica: Produto, Informações Ambientes Construídos e Transporte

$16^{\circ}$ USIHC - Congresso Internacional de Ergonomia e Usabilidade de Interfaces Humano Computador

CINAHPA | 2017 - Congresso Internacional de Ambientes Hipermídia para Aprendizagem.

SIERVI, Elizabeth M. C. de. Instrumentos de levantamento e tratamento de dados para apoio ao processo projetual de arquitetura e urbanismo: subsídios teórico-metodológicos. Pesquisa de Pós Doutorado - Relatório Circunstanciado.

Universidade Federal de Santa Catarina, UFSC, 2015.

KEPPE JUNIOR, Celso Luiz

Guimarães. Formulação de um indicador de acessibilidade das calçadas e travessias. 2008. 161 f. Dissertação (Mestrado) - Curso de Engenharia Civil, Universidade Federal de São Carlos, São Paulo, 2007

LUNARO, Adriana; FERREIRA, Marcos Antonio Garcia. OS ESPAÇOS PÚBLICOS E A QUESTÃO DA ACESSIBILIDADE SOB O PONTO DE VISTA DOS IDOSOS. 2005. $6 \mathrm{f}$. Monografia (Especialização) - Curso de Engenharia Cívil, Universidade Federal de São Carlos, São Carlos, 2005.

ERGODESIGN, 2006, Bauru. Projetos de espaços públicos livres de lazer para todos. Sao Paulo: Faac, 2006. $6 \mathrm{p}$

DUARTE, Cristiane Rose; COHEN,

Regina. PROPOSTA DE METODOLOGIA DE AVALIAÇÃO DA ACESSIBILIDADE AOS ESPAÇOS DE ENSINO

FUNDAMENTAL. 2006. 12 f. Monografia

(Especialização) - Curso de Arquitetura e Urbanismo, Universidade Federal do Rio de Janeiro, Rio de Janeiro, 2006

\section{Agradecimentos}

Os agradecimentos são para a fonte financiadora da pesquisa: PIBIC/CNPq/UNESC 